\title{
Vitamin D in the Prevention of Aromatase Inhibitor-Induced Musculoskeletal Symptoms: Is It Ready for Practice?
}

JEANNINE BRANT, PhD, APRN, AOCN ${ }^{\circledR}$

From Billings Clinic, Billings, Montana

Author's disclosures of potential conflict of interest are found at the end of this article.

Correspondence to: Jeannine Brant, PhD, APRN, AOCN® , Billings Clinic Inpatient Cancer Care, PO Box 37000, Billings, MT 59107.

E-mail: jbrant@billingsclinic.org

(c) 2012 Harborside Press ${ }^{\circledR}$
J Adv Pract Oncol 2012;3:245-257

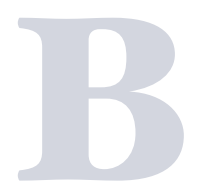

reast cancer is the most common malignancy in women. In 2012, approximately 226,870 new cases of breast cancer will be diagnosed in the United States (American Cancer Society, 2012). Depending on tumor characteristics and stage of disease, breast cancer treatment includes surgery, radiation therapy, chemotherapy, biologic therapy, and hormonal therapy.

Aromatase inhibitors (AIs), one type of hormonal therapy, are indicated in the treatment of estrogen receptorpositive breast cancer in postmenopausal women (National Comprehensive Cancer Network, 2012). Although tamoxifen was traditionally used in the treatment of hormone receptorpositive breast cancer, the randomized controlled ATAC (Arimidex, Tamoxifen, Alone or in Combination) trial $(\mathrm{N}=9,366)$ comparing tamoxifen with anastrozole (an AI) plus tamoxifen indicated that anastrozole reduced the risk of tumor recurrence in postmenopausal women with localized breast cancer by $40 \%$. Unfortunately, the use of anastrozole and other AIs is associated with musculoskeletal symptoms, including an increased risk of bone fractures and musculoskeletal pain (Howell et al., 2005). Symptoms can affect both adherence and quality of life (Chlebowski, 2009).

A recent study by Rastelli and colleagues (2011) suggests that vitamin D supplementation can decrease aromatase inhibitor-induced musculoskeletal symptoms (AIMSS). This article will discuss the problem of musculoskeletal symptoms with AI use, treatment strategies currently suggested in the literature, recent results of the vitamin D study by Rastelli and colleagues, and implications for advanced practitioners.

\section{Aromatase Inhibitor-Induced Musculoskeletal Symptoms}

Aromatase inhibitors can cause a multitude of musculoskeletal symptoms. While many aging women without cancer experience arthralgias and myalgias in their daily lives, clinical trials report that approximately 33\% of women taking AIs experience an 
increase in arthralgias (Howell et al., 2005). It is likely that the overall prevalence of arthralgias is underestimated; as ATAC's primary objective was breast cancer response, adverse effects may have been underreported (Sestak et al., 2008). Another trial examined musculoskeletal symptoms in postmenopausal women with nonmetastatic breast cancer who were about to start aromatase inhibitor therapy (Napoli et al., 2010). Arthralgias and myalgias were found in $61.3 \%$ and $43 \%$ of patients, respectively.

Little information is known about risk factors for musculoskeletal symptoms and the course of disease. Studies suggest that obese women and those who received prior chemotherapy may be at greater risk for arthralgias (Sestak et al., 2008). Vitamin D deficiency was noted in the majority of women with AIMSS (Napoli et al., 2010). Studies have suggested that for some women, arthralgias improve within 6 months of initiation, even while undergoing AI therapy. When arthralgias significantly impact quality of life, rotating to an alternative AI often results in a decrease in joint pain and swelling (Briot, Tubiana-Hulin, Bastit, Kloos, \& Roux, 2010; Fontaine et al., 2008). In addition to arthralgias, women undergoing AI therapy can experience carpal tunnel syndrome. Estrogen also contributes to bone mineral density (BMD). A major adverse effect related to AIs is a decrease in bone density, resulting in osteopenia and osteoporosis (Howell et al., 2005).

\section{Management of AIMSS}

Few trials have investigated interventions to manage arthralgias and other musculoskeletal symptoms in women taking AIs. One expert panel recommended selective COX-2 and nonselective nonsteroidal anti-inflammatory drugs, based on treatment of joint pain unrelated to AI administration (Coleman, Body, Gralow, \& Lipton, 2008). One study compared sham acupuncture (superficial needle insertion at nonacupoint locations) with true acupuncture (full body/auricular acupuncture and joint-specific point prescriptions) in 38 women with AIMSS. True acupuncture significantly improved joint pain and stiffness $(p<.001$; Crew et al., 2010).

As vitamin D plays an important role in bone health, supplementation is recommended for all postmenopausal women. Vitamin D has also sparked some interest for the management of
AIMSS as deficiency was noted in many arthralgia sufferers who were taking AIs. Trials using standard (400 IU per day) and high doses (50,000 IU per week) of vitamin $\mathrm{D}_{3}$ in postmenopausal women not taking AIs showed no improvement in arthralgias (Chlebowski, 2009). A small $(\mathrm{N}=50)$ prospective single-arm study examined the effect of high-dose vitamin D on musculoskeletal symptoms in breast cancer patients receiving the AI letrozole. Relief of joint pain was reported by $23 \%$ of patients, although this was not statistically significant (Khan, O'Dea, \& Sharma, 2010).

A larger trial aimed to establish a level of vitamin D to prevent or minimize arthralgia in a cohort of 290 women starting AI therapy. While all women received standard doses of vitamin $\mathrm{D}_{3}$ (800 IU) with calcium, those with a baseline vitamin $\mathrm{D}$ level less than $30 \mathrm{ng} / \mathrm{mL}$ also received $16,000 \mathrm{IU}$ of vitamin $\mathrm{D}_{3}$ every 2 weeks. Even with supplementation with higher doses, $50 \%$ of the women failed to reach adequate vitamin D levels at 3 months. Joint pain was attenuated in those who reached vitamin D levels of at least 40 ng/mL (Prieto-Alhambra et al., 2011).

\section{The Rastelli Vitamin D Trial}

The most notable study to date is a doubleblind placebo-controlled randomized phase II trial using vitamin D for AIMSS. Patients $(\mathrm{N}=60)$ were stratified according to baseline vitamin $\mathrm{D}$ (25-hydroxyvitamin D [25-OHD]) level (Rastelli et al., 2011). Those with moderately low levels, between 20 and $29 \mathrm{ng} / \mathrm{mL}$, were randomized to receive either high-dose vitamin $\mathrm{D}$ supplementation (50,000 IU) weekly for 8 weeks then monthly for 4 months, or placebo. Those with low levels, between 10 and $19 \mathrm{ng} / \mathrm{mL}$, were randomized to receive high-dose vitamin $\mathrm{D}$ for 16 weeks and then monthly for 2 months, or placebo. Symptoms were assessed at baseline and at 2, 4, and 6 months using the Brief Pain Inventory-Short Form (BPI), the Fibromyalgia Impact Questionnaire (FIQ), and the Health Assessment Questionnaire-Disability Index. Investigators also assessed BMD at baseline and at 6 months.

Results indicated that pain was significantly decreased in the high-dose vitamin $\mathrm{D}$ groups compared to the placebo groups according to the FIQ $(p=.0045)$ and several measures on the BPI: worst pain $(p=.04)$, average pain $(p=.0067)$, pain severity $(p=.04)$, and interference $(p=.034)$. When 
each of the groups were analyzed separately, those patients who received the vitamin D for 16 weeks had more statistically significant improvement in symptoms. In terms of BMD, the femoral neck decreased in the placebo group, but no change was noted in the high-dose vitamin D group $(p=.06)$.

No significant gastrointestinal adverse events were reported in the high-dose vitamin $\mathrm{D}$ groups. However, this was not a primary variable in the study, and specific measures of adverse events were not discussed. Five patients dropped out of the study due to hypercalcemia, four of whom were in the high-dose vitamin D groups (Rastelli et al., 2011). Gastrointestinal symptoms such as nausea and diarrhea have been reported with low-dose vitamin D supplementation (doses less than 1,000 IU/day). Hypercalcemia and increased renal disease can also ensue (Chlebowski, 2009). Further studies are needed to determine adverse events related to high-dose vitamin D in women with breast cancer who are receiving AIs.

\section{Future Directions}

While research suggests that the use of highdose vitamin D in the management of AIMSS is effective, additional studies are needed to determine exact dosing strategies, monitoring guidelines, and adverse effects. Two additional clinical trials are underway to investigate this problem: (1) A Randomized Trial to Evaluate the Benefit of High Dose Vitamin $\mathrm{D}_{3}$ on Aromatase Inhibitor Letrozole-Associated Musculoskeletal Symptoms and Fatigue (The VITAL Trial) and (2) Vitamin $\mathrm{D}_{3}$ Effects on Musculoskeletal Symptoms With Use of Aromatase Inhibitors (National Institutes of Health, 2012). Although the first trial is closed but ongoing, the second trial is currently accruing patients.

\section{Implications for Advanced Practitioners}

Advanced practitioners are on the front lines of symptom management. For those in breast cancer care, arthralgias are a common complaint among women and have a significant impact on quality of life. Some women are impacted to the degree that they are no longer adherent to therapy. The results of this study may prompt some practitioners to move this research directly into practice by prescribing and recommending high doses of vitamin D for patients with AIMSS; however, additional studies are needed to determine the overall safety and efficacy in the long-term use of high-dose vitamin D in women on AIs. Questions remain such as how often to dose, how long to continue treatment, what types of measures should be used to monitor patients, how often to monitor patients, and when to discontinue treatment due to adverse effects such as hypercalcemia.

Vitamin D is increasingly recognized for its positive health benefits aside from managing arthralgias in patients on AIs. Prevention of autoimmune disease, cancer, cardiovascular disease, depression, dementia, infectious diseases, and musculoskeletal decline are all mentioned in the literature (Haines \& Park, 2012). Some patients are at high risk for low 25-OHD levels, especially those individuals from northern communities who have limited sun exposure. Lack of vitamin $\mathrm{D}$ in the diet, liver and kidney disease, malabsorption, and medications such as phenytoin can also contribute to low levels. Advanced practitioners can take an active role in monitoring 25-OHD levels in high-risk patients and replacing vitamin $\mathrm{D}$ as needed to maintain normal levels (30-74 ng/mL). Monitoring for side effects is also important to ensure patient safety and wellbeing. Clinicians should be aware of the adverse effects of vitamin D and recognize these effects when recommending or prescribing vitamin $\mathrm{D}$. While it is rare, hypervitaminosis can occur (Haines \& Park, 2012; see Table 1).

It is unknown whether replacement of vitamin D to normal levels will alleviate AIMSS, but

$\begin{array}{ll}\begin{array}{l}\text { Table 1. Signs and Symptoms of Vitamin D } \\ \text { Hypervitaminosis }\end{array} \\ \text { Category } & \text { Symptom } \\ \text { Generalized } & \begin{array}{l}\text { Fatigue } \\ \text { Irritability }\end{array} \\ \text { Gastrointestinal } & \text { Anorexia } \\ & \text { Constipation } \\ & \text { Nausea and vomiting } \\ \text { Musculoskeletal } & \text { Muscle weakness } \\ \text { Renal } & \text { Kidney stones } \\ & \text { Renal insufficiency } \\ \text { Central nervous system } & \text { Irritability } \\ & \text { Confusion } \\ & \text { Slurred speech } \\ & \text { Unstable gait } \\ \text { Metabolic } & \text { Dehydration } \\ & \text { Hypercalcemia }\end{array}$


other benefits alone may improve quality of life for patients and prevent other health complications. Advanced practitioners should continue to keep watch for additional studies in the literature that will more thoroughly answer this question about vitamin D use for AIMSS.

\section{DISCLOSURE}

The author has no conflicts of interest to disclose.

\section{REFERENCES}

American Cancer Society. (2012). Cancer facts \& figures 2012. Retrieved from http://www.cancer.org/docroot/ stt/stt_0.asp

Briot, K., Tubiana-Hulin, M., Bastit, L., Kloos, I., \& Roux, C. (2010). Effect of a switch of aromatase inhibitors on musculoskeletal symptoms in postmenopausal women with hormone-receptor-positive breast cancer: The ATOLL (Articular Tolerance of Letrozole) study. Breast Cancer Research and Treatment, 120(1), 127-134. http:// dx.doi.org/10.1007/s10549-009-0692-7

Chlebowski, R. T. (2009). Aromatase inhibitor-associated arthralgias. Journal of Clinical Oncology, 27(30), 49324934. http://dx.doi.org/10.1200/jco.2009.23.3270

Coleman, R. E., Body, J. J., Gralow, J. R., \& Lipton, A. (2008). Bone loss in patients with breast cancer receiving aromatase inhibitors and associated treatment strategies. Cancer Treatment Reviews, 34(suppl 1), S31-S42. http:// dx.doi.org/10.1016/j.ctrv.2008.03.005

Crew, K. D., Capodice, J. L., Greenlee, H., Brafman, L., Fuentes, D., Awad, D.,...Hershman, D. L. (2010). Randomized, blinded, sham-controlled trial of acupuncture for the management of aromatase inhibitor-associated joint symptoms in women with early-stage breast cancer. Journal of Clinical Oncology, 28(7), 1154-1160. http:// dx.doi.org/10.1200/jco.2009.23.4708

Fontaine, C., Meulemans, A., Huizing, M., Collen, C., Kaufman, L., De Mey, J.,...De Greve, J. (2008). Tolerance of adjuvant letrozole outside of clinical trials. Breast, 17(4), 376-381. http://dx.doi.org/10.1016/j. breast.2008.02.006

Haines, S. T., \& Park, S. K. (2012). Vitamin D supplementation:
What's known, what to do, and what's needed. Pharmacotherapy, 32(4), 354-382. http://dx.doi.org/10.1002/ phar.1037

Howell, A., Cuzick, J., Baum, M., Buzdar, A., Dowsett, M., Forbes, J. F.,...Tobias, J. S. (2005). Results of the ATAC (Arimidex, Tamoxifen, Alone or in Combination) trial after completion of 5 years' adjuvant treatment for breast cancer. Lancet, 365(9453), 60-62. http://dx.doi. org/10.1016/s0140-6736(04)17666-6

Khan, Q. J., O'Dea, A. P., \& Sharma, P. (2010). Musculoskeletal adverse events associated with adjuvant aromatase inhibitors. Journal of Oncology, 2010, article ID 654348. http://dx.doi.org/10.1155/2010/654348

Napoli, N., Vattikuti, S., Ma, C., Rastelli, A., Rayani, A., Donepudi, R.,...Armamento-Villareal, R. (2010). High prevalence of low vitamin $\mathrm{D}$ and musculoskeletal complaints in women with breast cancer. Breast Journal, 16(6), 609616. http://dx.doi.org/10.1111/j.1524-4741.2010.01012.x

National Comprehensive Cancer Network. (2012). NCCN Clinical Practice Guidelines in Oncology (NCCN Guidelines) ${ }^{\circledR}$, Breast Cancer, Version I.2012. Retrieved from http://www.nccn.org/professionals/physician_gls/pdf/ breast.pdf

National Institutes of Health. (2012). ClinicalTrials.gov. Retrieved from http://clinicaltrials.gov/ct2/results?term=Vit amin $+\mathrm{D}+$ aromatase+inhibitor

Prieto-Alhambra, D., Javaid, M. K., Servitja, S., Arden, N. K., Martinez-Garcia, M., Diez-Perez, A.,...Nogues, X. (2011). Vitamin D threshold to prevent aromatase inhibitor-induced arthralgia: A prospective cohort study. Breast Cancer Research and Treatment, 125(3), 869-878. http://dx.doi.org/10.1007/s10549-010-1075-9

Rastelli, A. L., Taylor, M. E., Gao, F., Armamento-Villareal, R., Jamalabadi-Majidi, S., Napoli, N., \& Ellis, M. J. (2011). Vitamin D and aromatase inhibitor-induced musculoskeletal symptoms (AIMSS): A phase II, double-blind, placebo-controlled, randomized trial. Breast Cancer Research and Treatment, 129(1), 107-116. http://dx.doi. org/10.1007/s10549-011-1644-6

Sestak, I., Cuzick, J., Sapunar, F., Eastell, R., Forbes, J. F., Bianco, A. R., \& Buzdar, A. U. (2008). Risk factors for joint symptoms in patients enrolled in the ATAC trial: A retrospective, exploratory analysis. Lancet Oncology, 9(9), 866-872. http://dx.doi.org/10.1016/s14702045(08)70182-7

For another perspective on vitamin $D$ and cancer, see the article by Rita Wickham, $P h D, R N, A O C N{ }^{\circledR}$, that begins on the opposite page. 


\section{Cholecalciferol and Cancer: Is It a Big $\mathrm{D}_{3}$-eal?}

RITA WICKHAM, PhD, RN, AOCN ${ }^{\circledR}$

From Northern Michigan University, Marquette, Michigan

Author's disclosures of potential conflict of interest are found at the end of this article.

Correspondence to: Rita Wickham, PhD, RN, AOCN 8039 Garth Point Lane, Rapid River, MI 49878.

E-mail: rita_wickham@yahoo.com

(c) 2012 Harborside Press ${ }^{\otimes}$
J Adv Pract Oncol 2012;3:249-257 lthough the associations between cholecalciferol (hereafter referred to as vitamin D) and health are only beginning to be deciphered, we have adequate understanding to apply some concepts to the care of individuals with cancer. Vitamin $\mathrm{D}$, which is synthesized or ingested by every living organism, is essential to the function of all cells to maintain extracellular and intracellular calcium homeostasis, cell signaling, and regulation of numerous physiologic functions (Bikle, 2010).

The optimal amount of vitamin D humans need each day remains controversial, particularly in light of the current recommended daily intake (RDI) from the Institute of Medicine (IOM, 2011). This is an important consideration because $50 \%$ to $75 \%$ of Caucasians and as many as $90 \%$ of African Americans, Asians, and Latinos in the United States are vitamin D insufficient or deficient (Armas et al., 2007; Adams \& Hewison, 2010; Binkley, Ramamurthy, \& Krueger, 2010; Kennel, Drake, \& Hurley, 2010; Wimalawansa, 2012). These estimates are similar or worse in cancer patients or survivors; in one study of 413 women about to begin aromatase inhibitor (AI) therapy for breast cancer, only $13 \%$ had normal vitamin D levels before they started therapy (Singh, Cuzick, Mesher, Richmond, \& Howell, 2012). This may have other clinical consequences as well. For instance, the authors of a recent extensive review concluded that the low nutritional vitamin D status of African Americans may explain the unaccounted for disparity in cancer survival rates between African Americans and White Americans (Grant \& Peiris, 2012).

Low vitamin $\mathrm{D}$ has also been documented in some patients with other cancers, cardiovascular disease, autoimmune (e.g., rheumatoid arthritis and multiple sclerosis) or infectious conditions, osteoporosis, type 2 diabetes, and obesity and may increase the risk for cognitive impairment in elderly individuals (Grey \& Bolland, 2010; Hanley, Cranney, Jones, Whiting, \& Leslie, 2010; Pearce \& Cheetham, 2010). Most studies that examined such relationships were observational, so their strength and direction remain to be established in prospective trials. It is not known whether vitamin $\mathrm{D}$ deficiency and disease reflects a cause-and-effect re- 
lationship, or if the deficiency is a manifestation common to poor health.

A hot-off-the-presses meta-analysis of randomized clinical trials examined the effect of vitamin $D$ alone or with calcium on mortality in 88,097 elderly individuals (Rejnmark et al., 2012). The major study finding was that vitamin $\mathrm{D}(10-20 \mu \mathrm{g}$ [400-800 IU] per day) plus calcium (but not vitamin $\mathrm{D}$ alone) reduces mortality (absolute risk reduction, 0.66).

\section{What Is Vitamin D and Why Do We Need It?}

The "discovery" of vitamin D was driven by the high incidence of rickets during the Industrial Age, heralded by increased smog, decreased exposure to sunlight, and child labor. The hallmarks of rickets are painful or tender soft bones, short stature, muscle weakness, bone and teeth deformities, and reproductive problems secondary to skeletal defects. Around 1920, two discov-

\section{Table 1. The Institute of Medicine and Endocrine Society Recommendations for Use of Vitamin D}

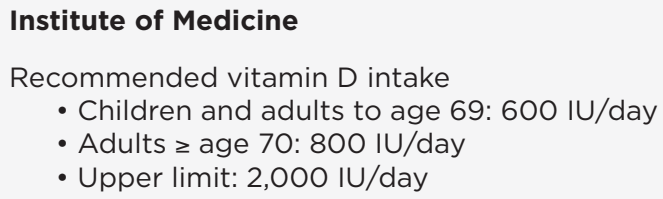

- Adults $\geq$ age 70: $800 \mathrm{IU} /$ day

- Upper limit: 2,000 IU/day

\section{Endocrine Society}

Population screening for vitamin D deficiency: Not recommended

Screen individuals at risk (serum 25(OH)D [calcidiol])

Recommended vitamin $D$ intake:

- Adults age 19-64: At least $600 \mathrm{IU} /$ day

- Age > 65: At least $800 \mathrm{lU} /$ day

- Unknown if these doses are sufficient to provide all the potential nonskeletal health benefits of vitamin D

- To raise serum calcidiol to consistently $>30 \mathrm{ng} / \mathrm{mL}$ may require at least 1,500-2,000 IU/day

- Maintenance tolerable upper limits (not to be exceeded without medical supervision): 4,000 IU/day

-10,000 IU/day for children and adults $\geq$ age 19 may be necessary to correct vitamin D deficiency

Adults who are vitamin $D$ deficient: Treat with 50,000 IU of vitamin $D_{2}$ or $D_{3}$ once a week for $8 \mathrm{wk}$ (or $6,000 \mathrm{IU}$ of vitamin $D_{2}$ or $D_{3}$ daily) to achieve a calcidiol $>30 \mathrm{ng} / \mathrm{mL}$

- Then maintenance therapy of 1,500-2,000 IU/day.

Patients who are obese, have malabsorption syndrome, or long-term use of medications affecting vitamin D metabolism (phenytoin, phenobarbital, carbamazepine, isoniazid, theophylline, glutethimide, rifampin, and glucocorticoids) require 2-3 times higher doses

- At least $6,000-10,000 \mathrm{IU} /$ day to treat vitamin $\mathrm{D}$ deficiency to maintain calcidiol $>30 \mathrm{ng} / \mathrm{mL}$

- Then maintenance therapy of 3,000-6,000 IU/day

Note. Information from IOM (2011) and Holick et al. (2011). eries were made: A factor that was identified in cod liver oil and named vitamin $\mathrm{D}$ (discovered after vitamins $\mathrm{A}, \mathrm{B}$, and $\mathrm{C}$ ) could prevent rickets in dogs, and ultraviolet light could cure rickets in children (DeLuca, 2008).

We now know that vitamin $\mathrm{D}$, often in conjunction with calcium, is involved in numerous body functions. Vitamin D promotes calcium absorption in the gut, maintains the bone-calcium hydroxyapatite structure critical to bone mineral density, is necessary for muscle function, maintains normal serum calcium and phosphate levels, and is involved in many celluar functions. Despite all of these functions, the current IOM RDIs address only the amount of itamin D that will prevent rickets in children and osteomalacia in adults. Some scientists and clinicians disagree with the IOM recommendations because the optimal serum levels of vitamin $\mathrm{D}$ metabolites for other essential roles are unknown; they propose measuring nutritional vitamin $\mathrm{D}$ (calcidiol) to determine individualized supplementation needs (Heaney \& Holick, 2011; Hollis, 2011). Similarly, the Endocrine Society recently published consensus-based guidelines regarding vitamin D (Holick et al., 2011), which are meant to help clinicians identify and evaluate patients at risk for vitamin $\mathrm{D}$ deficiency, as well as to guide efforts in prevention (see Table 1).

If it were identified today, vitamin $\mathrm{D}$ would not be called a vitamin-a vital nutrient that must be obtained in small amounts from the diet-but more correctly a prohormone essential to life. It is metabolized via two steps to a short-lived, biologically active pluripotent steroid hormone with numerous endocrine and paracrine functions (Norman, 2008). Vitamin D is highly conserved and found in virtually all plants and animals, even deep-ocean singlecell phytoplankton and zooplankton that have different mechanisms of production (Bikle, 2010). 
Animals synthesize $\mathrm{D}_{3}$ (cholecalciferol), whereas most plants and fungi synthesize $\mathrm{D}_{2}$ (ergocalciferol); these have slightly different chemical structures but are similarly metabolized.

As shown in Figure 1, after synthesis or ingestion, vitamin $\mathrm{D}$ is transported to the liver, where cytochrome P450 enzymes (CYP2R1, CYP2D11, and CYP2D25) hydroxylate it to an intermediate, measurable metabolite: $25(\mathrm{OH}) \mathrm{D}$ (calcidiol). Serum calcidiol is subsequently transported to the kidney, where parathyroid hormone (PTH) regulates mitochondrial CYP27B1 hydroxylation to the short-lived, active vitamin $\mathrm{D}$ metabolite: 1,25(OH)2D (calcitriol). When circulating calcidiol is sufficient, many cells (e.g., skin, brain, testes, intestine, lymph nodes, bone, cartilage, and placenta) elaborate CYP27B1 and directly synthesize calcitriol when needed for hormone or cytokine effects. These include monocytes and macrophages, in which calcitriol acts as a cytokine to modulate innate immunity (Adams \& Hewison, 2010).

Almost all cells express nuclear vitamin D receptors that mediate local actions of calcitriol and regulate the expression of more than 200 genes. These include adipose, adrenal, bone, bone marrow, brain, breast, colon, intestine, kidney, lung, B and $\mathrm{T}$ lymphocytes, cardiac and smooth muscle, ovarian, pancreatic beta cells, parathyroid, pituitary, prostate, skin, stomach, testis, thyroid, and uterine, as well as some cancer cells (Norman, 2008). Calcitriol is a powerful regulator of cellular growth in normal and cancer cells; it inhibits cellular proliferation and induces terminal differentiation, inhibits angiogenesis, stimulates insulin production, inhibits renin production, stimulates macrophage cathelicidin production, and stimulates its own destruction (Holick et al., 2011; Raisz, 2005; Stechschulte, Kirsner, \& Federman, 2009). In bone, calcitriol, along with PTH and IL6 , indirectly increases the receptor activator for nuclear KB ligand (Murthy et al., 2010).

On June 19, 2012, at the American Association for Cancer Research meeting focusing on pancreatic cancer, a presentation summarized the findings from two large studies in which a single nucleotide polymorphism (SNP, pronounced "snip") in the VDR gene called rs2853564 was related to survival in patients with advanced pancreatic cancer. Median overall survival was longest in patients homozygous for rs2853564 (inherited this allele from both parents), 8.9 to

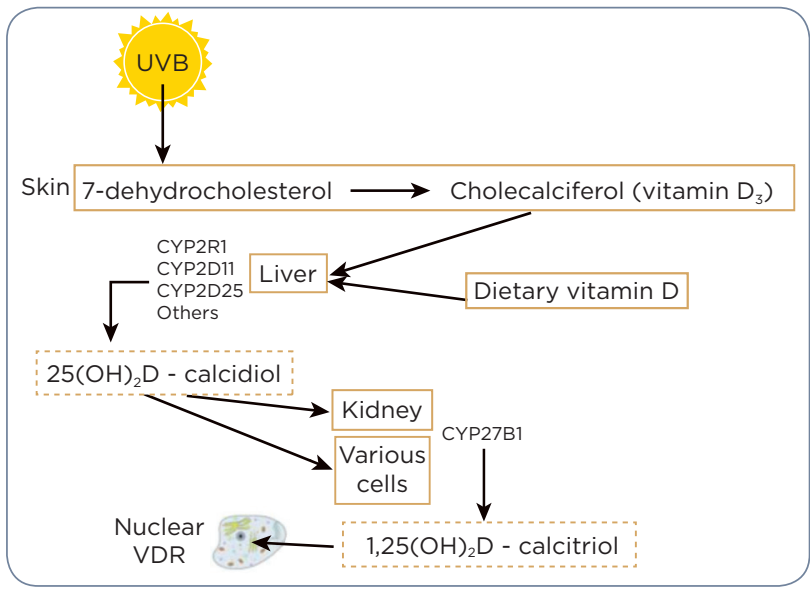

Figure 1. In the presence of UVB sunlight, animals and birds convert 7-dehydrocholesterol to vitamin $D_{3}$, which is transported by the bloodstream to the liver where both photosynthesized and ingested vitamin D are hydroxylated to calcidiol, a stable, inactive, and measurable intermediate metabolite. Serum calcidiol is then transported to the kidney and local tissues, where a second hydroxylation coverts it to the active, unmeasurable metabolite calcitriol. Calcitriol is present only for the brief time it takes to interact with vitamin $D$ receptors (VDRs) to cause biological effects.

10.5 months; shorter in heterozygous patients (inherited the rs2853564 allele from one parent and a different allele from the other parent), 5.9 to 8.3 months; and shortest in patients without an rs2853564 allele, 4.7 to 6.6 months (Innocenti et al., 2012). Confirmation of these data could spur renewed interest in vitamin D analogs as anticancer therapy.

\section{Why Is Vitamin D Deficiency So Common?}

In past times, humans got $90 \%$ of their vitamin D from ultraviolet B (UVB) sunlight and about 10\% from their diet. A "good diet" cannot prevent deficiency because few foods naturally contain vitamin D: mainly wild-caught oily ocean fish and egg yolks (Kennel et al., 2010). Consum-

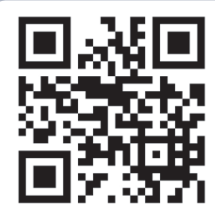

Use your smartphone to access the Institute of Medicine's Dietary Reference Intakes for Calcium and Vitamin D and the Endocrine

Society's clinical practice guideline on SEE PAGE 272 vitamin D deficiency. 
ing these and fortified foods results in a dietary vitamin D intake of about 150-200 IU (3.75-5 $\mu \mathrm{g})$ per day; see Table 2 for a list of foods and how much vitamin D they contain (Bailey et al., 2010; Holick \& Chen, 2008; Moyad, 2008).

UVB sunlight causes photoconversion of 7-dehydrocholesterol in the skin to cholecalciferol (vitamin $\mathrm{D}_{3}$ ). In much of the United States (north of $37^{\circ}$ latitude), synthesis varies depending on the season (highest in summer and lowest in winter) and the time of the day (UVB sunlight occurs from 10 a.m. to 3 p.m. from late spring to early fall; see Figure 2). Other factors that decrease vitamin D synthesis are wearing clothing or using sunscreen to block the sun's rays, staying out of the sun all together, aging (decreased dehydrocholesterol in skin lessens synthesis), and having darker skin (melanin blocks the sun's rays) (Armas et al., 2007).

\begin{tabular}{|c|c|c|}
\hline Food & $\begin{array}{l}\text { Serving } \\
\text { size }\end{array}$ & $\begin{array}{l}\text { Vitamin D } \\
\text { (IU) }\end{array}$ \\
\hline Cod liver oil & $1 \mathrm{tsp}$ & $\sim 400-1,000$ \\
\hline Wild salmon & $3.5 \mathrm{oz}$ & $\sim 600-1,000$ \\
\hline Canned salmon & $3.5 \mathrm{oz}$ & $\sim 300-600$ \\
\hline Oysters & $3 \mathrm{oz}$ & 545 \\
\hline Catfish & $3 \mathrm{oz}$ & 425 \\
\hline Farmed trout & $3 \mathrm{oz}$ & 375 \\
\hline Farmed salmon & $3.5 \mathrm{oz}$ & $\sim 100-275$ \\
\hline Bluefin tuna & $3 \mathrm{oz}$ & 170 \\
\hline Canned tuna & $3.5 \mathrm{oz}$ & $\sim 160-263$ \\
\hline Shrimp & $3 \mathrm{oz}$ & 120 \\
\hline Fortified milk, yogurt & $8 \mathrm{oz}$ & 100 \\
\hline Fortified orange juice & $8 \mathrm{oz}$ & 100 \\
\hline Fortified cereal & $8 \mathrm{oz}$ & 100 \\
\hline Cod & $3 \mathrm{oz}$ & 80 \\
\hline Sole or flounder & $3 \mathrm{oz}$ & 50 \\
\hline $\begin{array}{l}\text { Mushrooms } \\
\text { (chanterelle, shiitake) }\end{array}$ & $2 \mathrm{oz}$ & $\sim 50-55\left(D_{2}\right)$ \\
\hline $\begin{array}{l}\text { Swordfish or } \\
\text { freshwater bass }\end{array}$ & $3 \mathrm{oz}$ & 35 \\
\hline Egg (yolk) & 1 & $\sim 20-25$ \\
\hline
\end{tabular}

Note. $\mathrm{IU}=$ International Units. Information from Holick et al. (2011) and Moyad (2008).
Educational campaigns about the dangers of sun exposure with regard to skin cancers have dramatically increased vitamin D deficiency worldwide. Public health campaigns that espouse total sun avoidance do not take into account how humans normally synthesize vitamin D. As humans evolved in equatorial Africa, they lost body hair and developed sweat glands for cooling. Because the levels of UVB (and UVA) sunlight are highest at the equator, synthesizing vitamin $\mathrm{D}$ year round was not an issue. Melanin expression and dark skin are thought to have evolved to conserve folate necessary for reproduction. This was less necessary in groups of humans who migrated away from the equator and eventually came to have lighter skin that would not block as much UVB sunlight and more efficiently synthesize vitamin $\mathrm{D}_{3}$ (Jablonski \& Chaplin, 2002).

Recent increases in mobility and large-scale migration, along with sun avoidance, have led to the pandemic of vitamin $\mathrm{D}$ deficiency, particularly in darker-skinned persons. A reasonable rule of thumb for advising most patients about sensible sun exposure during the hours of 10 a.m. to 3 p.m. during late spring, summer, and autumn is that they should apply sunscreen after the time it takes to cause slight skin erythema at 24 hours ( 1 minimal erythemal dose [MED]): about 15 minutes for fair-skinned people, 30 minutes for Asian Indians, and up to 120 minutes for African Americans (Hollis, 2005).

In $1 \mathrm{MED}$, an adult wearing a swimsuit would synthesize about 10,000 to 25,000 IU of vitamin $\mathrm{D}_{3}$ (Holick, 2010). After $1 \mathrm{MED}$, no more cutaneous vitamin $\mathrm{D}_{3}$ synthesis occurs, but the risks for photoaging and skin cancers increase. So you can also advise your patients always to use sunscreen of at least SPF 15 on their face and hands, which will almost totally block cutaneous synthesis of vitamin $\mathrm{D}_{3}$, and to apply it to other exposed body parts after reaching their MED time (Armas et al., 2007; Sayre \& Dowdy, 2007).

\section{How Much Vitamin D Is Needed?}

The solution for most individuals is vitamin D supplementation. Both ergocalciferol $\left(D_{2}\right)$ and cholecalciferol $\left(\mathrm{D}_{3}\right)$ oral supplements are available (prescription and over-the-counter, respectively). $\mathrm{D}_{2}$ and $\mathrm{D}_{3}$ are equivalent when administered daily or weekly, but $\mathrm{D}_{3}$ has a longer half-life and greater affinity for D-binding proteins than does $\mathrm{D}_{2}$ and leads to more consistent 


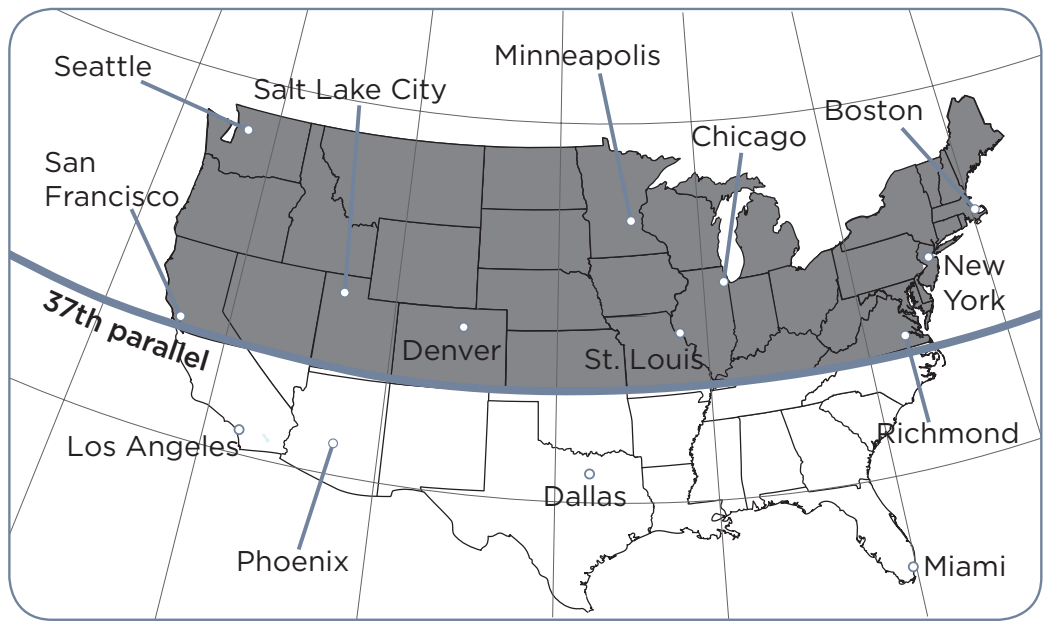

Figure 2. Americans living north of $37^{\circ}$ latitude (shaded area) are at greater risk for vitamin $D$ deficiency because of low or absent UVB sunlight from late October to late April. consider levels from $54-90 \mathrm{ng} / \mathrm{mL}$ (in persons who work outside without being overly clothed) as normal and levels $<32 \mathrm{ng} / \mathrm{mL}$ as deficient. In the same vein, we do not have a way to establish normal population vitamin D levels (Wimalawansa, 2012). These are important considerations, particularly because most studies involving the health effects of vitamin $\mathrm{D}$ have been retrospective, no standard doses of vitamin D have been used, serum calcidiol levels were frequently not assessed, and current definitions of recommended and upper limit doses may or may not reflect actual effects. levels when administered at longer intervals (Wimalawansa, 2012).

The most widely publicized recommendations are from the IOM (2011); they are assumed to result in nutritional vitamin $\mathrm{D}$ (calcidiol) levels sufficient to prevent rickets in children, osteomalacia in adults, and falls in the elderly. Given the high incidence of vitamin D deficiency, the IOM RDIs may not be sufficient to increase or maintain "normal" or "optimal" vitamin D levels, which are more accurately measured by circulating serum calcidiol status. On the other hand, the Endocrine Society recommends similar RDIs for the general population but also advises screening for vitamin $\mathrm{D}$ deficiency, which certainly includes many patients with cancer, by checking calcidiol levels and more aggressively managing these patients; see Table 1 (Hollis, 2011).

There are no universally agreed-upon definitions for overall normal and deficient calcidiol values. A level of $\leq 20 \mathrm{ng} / \mathrm{mL}$ (or $50 \mathrm{nmol} / \mathrm{L}$ ) is considered "deficiency" and can lead to impaired bone mineralization, with rickets in children or osteomalacia in adults (Binkley, Ramamurthy, \& Krueger, 2010; Grey \& Bolland, 2010; Khan et al., 2010; IOM, 2011); a level of 21-31 ng/mL (52.5-77.5 $\mathrm{nmol} / \mathrm{L}$ ) is considered "insufficiency" and may be associated with long-term adverse health and bone effects; and 32-100 ng/mL (80-250 nmol/L) is the "normal" calcidiol range.

However, previous methods to establish normal calcidiol levels may have been flawed. Hollis (2005) proposed that it would make more sense to

\section{Potential Problems Related to Vitamin D Deficiency}

The vitamin D deficiency literature is growing at a phenomenal rate. In terms of cancer patients or survivors, this means we are reading more about potential relationships of vitamin $\mathrm{D}$ deficiency and aromatase inhibitor-induced musculoskeletal symptoms (AIMSS) as well as cancer and cancer mortality, impaired bone health (osteoporosis or osteomalacia), and adverse effects with administration of bisphosphonates or denosumab (Prolia, Xgeva). Vitamin D deficiency may be accompanied by subtle and nonspecific manifestations: generalized bone discomfort possibly elicited with pressure on the sternum or tibia, lethargy, worsening of chronic disease, rheumatoid arthritis, muscle aches, osteoporosis, low back pain (in women), proximal muscle weakness and increased risk for falls, difficulty losing weight, or proximal myopathy potentially misdiagnosed as fibromyalgia, chronic fatigue syndrome, or arthritis (Bordelon, Ghetu, \& Langan, 2009; Wimalawansa, 2012).

A comprehensive discussion of vitamin $\mathrm{D}$ deficiency and cancer occurrence and mortality is beyond the scope of this article. Interest has been spurred by ecologic studies that noted the incidence and prevalence of some cancers increase with greater distance from the equator and that cancer survival is better for individuals diagnosed in summer months when UVB sunlight is available (Bell, 2011; Krishnan, Trump, Johnson, \& Feldman, 2010). The possible connection 
between vitamin $\mathrm{D}$ and cancer is hypothesized because vitamin $\mathrm{D}$ has antiproliferative and differentiation roles, inhibits telomerase expression and angiogenesis, and induces apoptosis. Vitamin D may also exert anticancer effects by influencing gene transcription and cell signaling, have other cell cycle effects (Fleet, Desmet, Johnson, \& Li, 2012), and may also reduce invasion and metastases (Krishnan et al., 2010).

A recent meta-analysis of prospective randomized and observational studies suggested that high-dose vitamin D (1,000 IU/day) can decrease the total risk for cancer and that each $4 \mathrm{ng} / \mathrm{mL}$ increase in serum calcidiol decreases the risk for colorectal cancer (but not breast or prostate cancer) by 6\% (Chung, Lee, Terasawa, Lau, \& Trikalinos, 2011). Calcidiol levels as high as $60-80 \mathrm{ng} / \mathrm{mL}$ may be needed to reduce cancer risk (Garland, French, Baggerly, \& Heaney, 2011).

As discussed on page 245 by Jeannine Brant, $\mathrm{PhD}, \mathrm{APRN}, \mathrm{AOCN}^{\circledR}$, advanced practitioners (APs) frequently encounter AIMSS. Somewhere between $18 \%$ and $45 \%$ of breast cancer patients develop AIMSS, usually within 2 months of starting AI therapy. Manifestations include bilateral joint pain and stiffness (hands, shoulders, lower back, hips, knees, and feet) and possible morning stiffness, sleep problems, fatigue, and functional impairment (Burstein, 2007; Khan et al., 2010; Winters, Habin, Flanagan, \& Cashavelly, 2009). Unrelieved pain is the most common reason for discontinuing a prescribed AI (Dent, Gaspo, Kissner, \& Pritchard, 2011), and symptoms may be worst in young women (ages 35-50) with ovarian failure secondary to chemotherapy or surgery (Al-Janadi et al., 2010).

Unrecognized vitamin D deficiency can also cause painful osteomalacia that may be misdiagnosed as bone metastases on x-ray (Khokhar, Brett, \& Desai, 2009). Another serious complication can occur after bisphosphonate administration (e.g., zoledronic acid or pamidronate) to vitamin D-deficient patients: severe and potentially life-threatening hypocalcemia (reported levels $5.2-9 \mathrm{mg} / \mathrm{dL}$ to $6.9 \mathrm{mg} / \mathrm{dL}$ ) accompanied by cardiac abnormalities and with elevated (1.2-2.6 $\mathrm{mg} / \mathrm{dL}$ ) serum creatinine levels (Breen \& Shane, 2004; Broadbent, Glare, \& Crawford, 2005; Rosen \& Brown, 2003; Wang-Gillam, Miles, \& Hutchins, 2008). Hypocalcemia can also occur with denosumab administration, but there is no informa- tion on whether vitamin D deficiency increases risk (Henry et al., 2011).

\section{Implications for Advanced Practitioners}

When AI therapy is planned, the advanced practictioner should have an in-depth discussion with patients regarding possible side effects as well as benefits of therapy, remind them about the importance of adherence and possible interventions if AIMSS occurs, and document baseline musculoskeletal symptoms. A baseline serum calcidiol level may be indicated because many breast cancer patients are vitamin D deficient, which may be a factor for worsening AIMSS.

Two prospective studies examined the effects of vitamin D levels and supplementation on AIMSS-related arthralgia. One study stratified 60 breast cancer patients about to begin an AI by calcidiol levels: Those with levels $\leq 40 \mathrm{ng} / \mathrm{mL}$ were assigned to high-dose vitamin D supplementation of 50,000 IU oral vitamin D every week for 12 weeks, and those $>40 \mathrm{ng} / \mathrm{mL}$ continued $600 \mathrm{IU} /$ day (Khan et al., 2010). Sixteen weeks after starting an AI, women whose calcidiol was $>66 \mathrm{ng} / \mathrm{mL}$ were significantly more likely to have less pain and no disability from AIMSS than were women with calcidiol levels $<66 \mathrm{ng} / \mathrm{mL}(p=.008)$.

In a second prospective study, Prieto-Alhambra et al. (2011) identified 260 postmenopausal breast cancer patients about to begin AI therapy who had calcidiol levels of $<30 \mathrm{ng} / \mathrm{mL}$. They were treated with oral calcium (1 g) and vitamin D (800 IU) daily plus oral vitamin D 16,000 IU every 2 weeks for 3 months. At the end of this study period, women whose calcidiol was $>40 \mathrm{ng} / \mathrm{mL}$ were less likely to develop joint pain than those with levels of $<40 \mathrm{ng} / \mathrm{mL}(p=.008)$. However, only about half of these patients treated with high doses of vitamin D used in this study (cumulative dose $=280,000 \mathrm{IU}$ ) had a serum calcidiol of $>30 \mathrm{ng} / \mathrm{mL}$ at the end of the study. These two studies illustrate that vitamin D may be helpful in alleviating AIMSS, but vitamin $\mathrm{D}$ deficiency is a significant problem, and patients with breast cancer receiving an $\mathrm{AI}$ may require higher doses of vitamin $\mathrm{D}$ and more frequent monitoring to achieve a level of $>40-65 \mathrm{ng} / \mathrm{mL}$.

Some patients may be reluctant to start or continue vitamin $\mathrm{D}$ because of recent reports in the lay literature that the United States Preventive Services Task Force has recommended that 
women should not take vitamin $\mathrm{D}$, with or without calcium, to prevent osteoporotic fractures or cancer (Kolata, 2012). Patients can be reminded that this is a draft recommendation that has been posted for public comment, and that their reason for taking vitamin $\mathrm{D}$ is different.

Anecdotal reports suggest that AIMSS may be lessened or controlled with analgesics (a nonsteroidal anti-inflammatory drug, a COX-2 inhibitor, tramadol, or an opioid), or another agent (e.g., glucosamine plus chondroitin sulfate, an anticonvulsant, or topical methylsalicylate) may be effective for many patients (Crew et al., 2007; Crew et al., 2010; Dent et al., 2011). Nonpharmacologic strategies that have been suggested to add possible benefit include hot packs, transcutaneous electrical nerve stimulation, massage therapy, acupuncture or acupressure, and psychological interventions. Arthralgias may thus be manageable, decreasing the risk of nonadherence to AI therapy. It is also critical to check serum calcidiol levels in patients who are to receive bisphosphonates or denosumab as part of their therapy or to prevent or treat osteoporosis, so they do not experience severe, life-threatening hypocalcemia. Similarly, this is important for patients who are thought to have bone metastases on x-ray that are subsequently confirmed to be related to osteomalacia.

The issue of screening and supplementation presents a dilemma for APs: Routine calcidiol monitoring is not recommended, and there are no specific recommendations for cancer patients, many of whom are vitamin $\mathrm{D}$ deficient. It seems clear that APs can make a case that calcidiol screening is justifiable when identifying vitamin D deficiency, when it may affect treatment outcomes or mortality in certain patients. These include breast cancer patients receiving an AI or tamoxifen, prostate cancer patients on androgen-deprivation therapy, and perhaps patients with colorectal or other cancers (Moyad, 2008).

A second issue is when to reassess serum calcidiol. If a patient is started on a standard dose of vitamin D (e.g., 600-800 IU/day), levels should be rechecked in 3 to 4 months, which is the time it takes for serum calcidiol levels to plateau (Hanley et al., 2010). On the other hand, patients who are given high doses of vitamin $\mathrm{D}$ to correct a deficiency should be checked in about 1 month, when peak levels are achieved.
The question of how much supplemental vitamin $\mathrm{D}$ to recommend or prescribe, especially for patients with insufficiency, has no clear answer. Hanley et al. (2010) indicated that calcidiol levels increase by $0.28-0.8 \mathrm{ng} / \mathrm{mL}$ for each 40 IU of daily vitamin D. For example, the amount of extra vitamin D needed to raise a patient's calcidiol from 25 to $40 \mathrm{ng} / \mathrm{mL}$ would be 750 to 2,143 IU/day. At-risk individuals may need more than the usually accepted doses of vitamin D supplements (e.g., 2,000-5,000 IU/day or 50,000 IU every 1 to 4 weeks) to maintain physiological levels of serum vitamin D and good health. Many endocrinologists prefer their patients to maintain serum vitamin $\mathrm{D}$ levels between 30 and $40 \mathrm{ng} / \mathrm{mL}$ (75-100 nmol/L).

Another suggestion is to match vitamin $\mathrm{D}$ supplementation to calcidiol level (Wimalawansa, 2012). When serum calcidiol is $<10 \mathrm{ng} / \mathrm{mL}$, give $50,000 \mathrm{IU}$ 3 times/wk; for levels of 11 to $20 \mathrm{ng} / \mathrm{mL}$, administer 50,000 IU twice a week; and for 21 to $29 \mathrm{ng} / \mathrm{mL}$, administer 50,000 IU once a week. Each regimen is recommended for 6 to 10 weeks. Once vitamin D levels are normalized, patients should receive maintenance doses of 1,000-2,000 IU per day, 10,000 IU once a week, or 50,000 IU of vitamin $\mathrm{D}_{3}$ once a month to prevent reverting to vitamin $\mathrm{D}$ deficiency.

Vitamin D toxicity is unlikely to occur with dosages of less than 5,000 IU per day; some studies have confirmed that it is safe to take up to $10,000 \mathrm{IU}$ per day (Wimalawansa, 2012). In fact, vitamin D toxicity is rare and does not occur unless an individual consistently takes at least 40,000 IU/day for several months (Hanley et al., 2010). Manifestations of vitamin D toxicity mirror hypercalcemia: nausea, dehydration, headache, irritability, constipation, hypercalciuria and hyperphosphatemia, and polyuria (Kennel et al., 2010; Wimalawansa, 2012). Most patients with vitamin D toxicity have calcidiol levels $>150 \mathrm{ng} / \mathrm{mL}$.

\section{Conclusion}

In conclusion, APs are vital to maintaining cancer patients' safety and quality of life by assisting them in maintaining optimal vitamin $\mathrm{D}$ levels. In addition, some breast cancer patients may require aggressive and creative symptom management strategies to alleviate arthralgias related to AIMSS.

\section{DISCLOSURE}

The author has no conflicts of interest to disclose. 


\section{REFERENCES}

Adams, J. S., \& Hewison, M. (2010). Update in vitamin D. Journal of Clinical Endocrinology \& Metabolism, 95, 471478. http://dx.doi.org/10.1210/jc.2009-1773

Al-Janadi, A., Hrinczenko, B., Chaudhary, V., Chitneni, S., Ali, S., Saultz, J., \& Dimitrov, N. V. (2010). Musculoskeletal events associated with the management of endocrineresponsive breast cancer. Oncology Reviews, 4, 185-189. http://dx.doi.org/10.1007/s12156-010-0057-9

Armas, L. G., Dowell, S., Akhter, M., Duthuluru, S., Huerter, C., Hollis, B. W.,...Heaney, R. P. (2007). Ultraviolet-B radiation increases serum 25-hydroxyvitamin D levels: The effect of UVB dose and skin color. Journal of the American Academy of Dermatology, 57, 583-593. http:// dx.doi.org/10.1016/j.jaad.2007.03.004

Bailey, R. L., Dodd, K. W., Goldman, J. A., Gahche, J. J., Dwyer, J. T., Moshfegh, A. J.,...Picciano, M. F. (2010). Estimation of total usual calcium and vitamin $\mathrm{D}$ intakes in the United States. Journal of Nutrition, 140, 817-822. http://dx.doi.org/10.3945/jn.109.118539

Bell, D. S. H. (2011). Protean manifestations of vitamin D deficiency, part 2: Deficiency and its association with autoimmune disease, cancer, infection, asthma, dermopathies, insulin resistance, and type 2 diabetes. Southern Medical Journal, 104, 335-344. http://dx.doi. org/10.1097/01.SMJ.0000397893.94525.0e

Bikle, D. D. (2010). Vitamin D: An ancient hormone. Experimental Dermatology, 20, 70-83.

Binkley, N., Ramamurthy, R., \& Krueger, D. (2010). Low vitamin D status: Definition, prevalence, consequences, and correction. Endocrinology and Metabolism Clinics of North America, 39, 287-301. http://dx.doi.org/10.1016/j. ecl.2010.02.008

Bordelon, P., Ghetu, M. V., \& Langan, R. (2009). Recognition and management of vitamin D deficiency. American Family Physician, 80, 841-846.

Breen, T. L., \& Shane, E. (2004). Prolonged hypocalcemia after treatment with zoledronic acid in a patient with prostate cancer and vitamin D deficiency (letter). Journal of Clinical Oncology, 22, 1531-1532. http://dx.doi. org/10.1200/JCO.2004.99.013

Broadbent, A., Glare, P., \& Crawford, B. (2005). Bisphosphonate-induced hypocalcemia associated with vitamin $\mathrm{D}$ deficiency in a patient with advanced cancer. American Journal of Hospice \&t Palliative Care, 22, 382-384. http:// dx.doi.org/10.1177/104990910502200512

Burstein, H. J. (2007). Aromatase inhibitor-associated arthralgia syndrome. Breast, 16, 223-234. http://dx.doi. org/10.1016/j.breast.2007.01.011

Chung, M., Lee, J., Terasawa, T., Lau, J., \& Trikalinos, T. A. (2011). Vitamin D with or without calcium supplementation for prevention of cancer and fractures: An updated meta-analysis for the U.S. Preventive Services task force. Annals of Internal Medicine, 155, 827-838.

Crew, K. D., Greenlee, H., Capodice, J., Raptis, G., Brafman, L., Fuentes, D.,...Hershman, D. L. (2007). Prevalence of joint symptoms in postmenopausal women taking aromatase inhibitors for early-stage breast cancer. Journal of Clinical Oncology, 25, 3877-3883. http://dx.doi. org/10.1200/JCO.2007.10.7573

Crew, K. D., Capodice, J. L., Greenlee, H., Brafman, L., Fuentes, D., Awad, D.,...Hershman, D. L. (2010). Randomized, blinded, sham-controlled trial of acupuncture for the management of aromatase inhibitor-associated joint symptoms in women with early-stage breast cancer. Journal of Clinical Oncology, 29, 1154-1160. http://dx.doi.
org/10.1200/JCO.2009.23.4708

DeLuca, H. F. (2008). Evolution of our understanding of vitamin D. Nutrition Reviews, 66(suppl 2), S73-S87. http:// dx.doi.org/10.1111/j.1753-4887.2008.00105.x

Dent, S. F., Gaspo, R., Kissner, M., \& Pritchard, K. I. (2011). Aromatase inhibitor therapy: Toxicities and management strategies in the treatment of postmenopausal women with hormone-sensitive early breast cancer. Breast Cancer Research and Treatment, 126, 295-310. http://dx.doi.org/10.1007/s10549-011-1351-3

Fleet, J. C., Desmet, M., Johnson, R., \& Li, Y. (2012). Vitamin D and cancer: A review of molecular mechanisms. Biochemical Journal, 441, 61-76. http://dx.doi.org/10.1042/ BJ20110744

Garland, C. F., French, C. B., Baggerly, L. L., \& Heaney, R. P. (2011). Vitamin D supplement doses and serum 25-hydroxyvitamin $\mathrm{D}$ in the range associated with cancer prevention. Anticancer Research, 31, 607-611.

Grant, W. B., \& Peiris, A. N. (2012). Differences in vitamin D status may account for unexplained disparities in cancer survival rates between African and White Americans. Dermato-Endocrinology, 4(2). Retrieved from http:// www.landesbioscience.com/journals/dermatoendocrinology/article/19667/?show_full_text=true

Grey, A., \& Bolland, M. (2010). Vitamin D. A place in the sun? Archives of Internal Medicine, 170, 1099-1100. http:// dx.doi.org/10.1001/archinternmed.2010.174

Hanley, D. A., Cranney, A., Jones, G., Whiting, S. J., \& Leslie, W. D. (2010). Vitamin D in adult health and disease: A review and guideline statement from Osteoporosis Canada (summary). Canadian Medical Association Journal, 182, 1315-1319. http://dx.doi.org/10.1503/cmaj.091062

Heaney, R. P., \& Holick, M. F. (2011). Why the IOM recommendations for vitamin $\mathrm{D}$ are deficient. Journal of Bone and Mineral Research, 26, 455-457. http://dx.doi. org/10.1002/jbmr.328

Henry, D. H., Costa, L., Goldwasser, F., Hirsh, V., Hungria, V., Prausova, J.,...Yeh, H. (2011). Randomized, double-blind study of denosumab versus zoledronic acid in the treatment of bone metastases in patients with advanced cancer (excluding breast and prostate cancer) or multiple myeloma. Journal of Clinical Oncology, 29, 1125-1132. http://dx.doi.org/10.1200/JCO.2010.31.3304

Holick, M. F. (2010). Vitamin D: Extraskeletal health. Endocrinology and Metabolism Clinics of North America, 39, 381-400. http://dx.doi.org/10.1016/j.ecl.2010.02.016

Holick, M. F., Binkley, N. C., Bischoff-Ferrari, H. A., Gordon, C. M., Hanley, D. A., Heaney, R. P.,...Weaver, C. M. (2011). Evaluation, treatment, and prevention of vitamin D deficiency: An Endocrine Society clinical practice guideline. Journal of Clinical Endocrinology \& Metabolism, 96, 1911-1930. http://dx.doi.org/10.1210/jc.2011-0385

Holick, M. F., \& Chen, T. C. (2008). Vitamin D deficiency: A world-wide problem with health consequences. American Journal of Clinical Nutrition, 87(suppl), 1080S$1086 \mathrm{~S}$.

Hollis, B. W. (2005). Symposium: Vitamin D insufficiency: A significant risk factor in chronic diseases and potential disease-specific biomarkers of vitamin D sufficiency. Journal of Nutrition, 135, 317-322.

Hollis, B. W. (2011). Short-term and long-term consequences and concerns regarding valid assessment of vitamin D deficiency: Comparison of recent food supplementation and clinical guidance reports. Current Opinion in Clinical Nutrition \& Metabolic Care, 14, 598-604. http:// dx.doi.org/10.1097/MCO.0b013e32834be798 
Innocenti, F., Venook, A. P., McLeod, H. L., Nakamura, Y., Ratain, M. J., Peterson, G. M.,...Kindler, H. L. (2012). Role of vitamin D receptor (VDR) gene polymorphisms for overall survival in pancreatic cancer: Genomewide association and functional mechanistic studies. Presented at the American Association for Cancer Research's Pancreatic Cancer: Progress and Challenges conference, Lake Tahoe, NV, June 18-21, 2012. Retrieved from http://media.chemotherapyadvisor.com/ documents/37/aacr_2012_innocenti_abstract_9008.pdf

Institute of Medicine. (2011). Dietary Reference Intakes for Calcium and Vitamin D. Washington, DC, The National Academies Press. Retrieved from http://books.nap. edu/openbook.php?record_id=13050

Jablonski, N. G., \& Chaplin, G. (2002). Skin deep. Scientific American, October, 74-81. http://dx.doi.org/10.1038/ scientificamerican1002-74

Kennel, K. A., Drake, M. T., \& Hurley, D. L. (2010). Vitamin $\mathrm{D}$ deficiency in adults: When to test and how to treat. Mayo Clinic Proceedings, 85, 752-758. http://dx.doi. org/10.4065/mcp.2010.0138

Khan, Q. J., Reddy, P. S., Kimler, B. F., Sharma, P., Baxa, S. E., O’Dea, A. P.,...Fabian, C. J. (2010). Effect of vitamin $\mathrm{D}$ supplementation on serum 25-hydroxy vitamin D levels, joint pain, and fatigue in women starting adjuvant letrozole treatment for breast cancer. Breast Cancer Research and Treatment, 119, 111-118. http://dx.doi. org/10.1007/s10549-009-0495-x

Khokhar, J. S., Brett, A. S., \& Desai, A. (2009). Vitamin D deficiency masquerading as metastatic cancer: A case series. American Journal of the Medical Sciences, 337, 245247. http://dx.doi.org/10.1097/MAJ.0b013e3181898525

Kolata, G. (2012, June 12). Healthy women advised not to take calcium and vitamin $\mathrm{D}$ to prevent fractures. The New York Times. Retrieved from http://www.nytimes. com/2012/06/13/health/calcium-and-vitamin-d-ineffective-for-fractures-us-preventive-services-taskforce-says.html

Krishnan, A. V., Trump, D. L., Johnson, C. S., \& Feldman, D. (2010). The role of vitamin D in cancer prevention and treatment. Endocrinology \& Metabolism Clinics of North America, 39, 401-418. http://dx.doi.org/10.1016/j. ecl.2010.02.011

Moyad, M. A. (2008). Vitamin D: A rapid review. Urologic Nursing, 28, 345-349, 384.

Norman, A. W. (2008). From vitamin D to hormone D: Fundamentals of the vitamin D endocrine system essential for good health. American Journal of Clinical Nutrition, 88(suppl), 491S-499S.

Pearce, S. H., \& Cheetham, T. D. (2010). Diagnosis and management of vitamin D deficiency. British Medical Jour- nal, 340, 142-147. http://dx.doi.org/10.1136/bmj.b5664

Prieto-Alhambra, D., Javaid, M. K., Servitja, S., Arden, N. K., Martinez-Garcı, M., Diez-Perez, A.,...Nogues, X. (2011). Vitamin D threshold to prevent aromatase inhibitor-induced arthralgia: A prospective cohort study. Breast Cancer Research and Treatment, 125, 869-878. http://dx.doi.org/10.1007/s10549-010-1075-9

Raisz, L. G. (2005). Pathogenesis of osteoporosis: Concepts, conflicts, and prospects. Journal of Clinical Investigation, 115, 3318-3325. http://dx.doi.org/10.1172/JCI27071

Rejnmark, L., Avenell, A., Masud, T., Anderson, F., Meyer, H. E., Sanders, K. M.,...Abrahamsen, B. (2012). Vitamin D with calcium reduces mortality: Patient level pooled analysis of 70,528 patients from eight major vitamin D trials. Journal of Clinical Endocrinology \& Metabolism, E-pub ahead of print May 17, 2012. http://dx.doi. org/10.1210/jc.2011-3328

Rosen, C. J., \& Brown, S. (2003). Severe hypocalcemia after intravenous bisphosphonate therapy in occult vitamin D deficiency (letter). New England Journal of Medicine, 348, 1503-1504. http://dx.doi.org/10.1056/ NEJM200304103481521

Sayre, R. M., \& Dowdy, J. C. (2007). Darkness at noon: Sunscreens and vitamin D3. Photochemistry and Photobiology, 83, 459-463. http://dx.doi.org/10.1562/2006-06-29RC-956

Singh, S., Cuzick, J., Mesher, D., Richmond, B., \& Howell, A. (2012). Effect of baseline serum vitamin D levels on aromatase inhibitors induced musculoskeletal symptoms: Results from the IBIS-II, chemoprevention study using anastrozole. Breast Cancer Research and Treatment, 132, 625-629. http://dx.doi.org/10.1007/s10549-011-1911-6

Stechschulte, S. A., Kirsner, R. S., \& Federman, D. G. (2009). Vitamin D: Bone and beyond, rationale and recommendations for supplementation. American Journal of Medicine, 122, 793-802. http://dx.doi.org/10.1016/j.amjmed.2009.02.029

Wang-Gillam, A., Miles, D. A., \& Hutchins, L. F. (2008). Evaluation of vitamin D deficiency in breast cancer patients on bisphosphonates. Oncologist, 13, 821-827. http:// dx.doi.org/10.1634/theoncologist.2008-0013

Wimalawansa, S. J. (2012). Vitamin D: An essential component for skeletal health. Annals of New York Academy of Science, 1240, E1-E12. http://dx.doi.org/10.1111/j.17496632.2011.06374.x

Winters, N., Habin, K., Flanagan, J., \& Cashavelly, B. (2009). "I feel like I am 100 years old!" Managing arthralgias from aromatase inhibitors. Clinical Journal of Oncology Nursing, 14, 379-382. http://dx.doi.org/10.1188/10. CJON.379-382 